\title{
The development of $\mathrm{YBa}_{2} \mathrm{Cu}_{3} \mathrm{O}_{x}$ thin films using a fluorine-free sol-gel approach for coated conductors
}

\author{
Donglu Shi ${ }^{1}$, Yongli Xu${ }^{1}$, Haibo $\mathrm{Yao}^{2}, \mathrm{Z} \mathrm{Han}^{2}$, Jie $\mathrm{Lian}^{3}$, \\ Lumin Wang ${ }^{3}$, Aihua $\mathrm{Li}^{4}$, H K Liu ${ }^{4}$ and S X Dou ${ }^{4}$ \\ ${ }^{1}$ Department of Materials Science and Engineering, University of Cincinnati, Cincinnati, \\ OH 45221, USA \\ ${ }^{2}$ Applied Superconductivity Research Center, Tsinghua University, Beijing 100084, \\ People's Republic of China \\ ${ }^{3}$ Department of Nuclear Engineering and Radiological Science, University of Michigan, \\ Ann Arbor, MI 48109, USA \\ ${ }^{4}$ Institute of Superconducting and Electronic Materials, University of Wollongong, \\ Wollongong, NSW, Australia
}

Received 23 March 2004, in final form 26 July 2004

Published 2 November 2004

Online at stacks.iop.org/SUST/17/1420

doi:10.1088/0953-2048/17/12/011

\begin{abstract}
Despite great success in the TFA methods of depositing $\mathrm{YBa}_{2} \mathrm{Cu}_{3} \mathrm{O}_{x}$ (YBCO) thin films for coated conductors, critical issues involved in removing $\mathrm{BaCO}_{3}$ have not entirely been settled. There could be other possible ways of dealing with carbon that remains in the film. We have recently developed a fluorine-free sol-gel synthesis with several important advantages including precursor solution stability, improved film density, and elimination of HF during processing. With this approach, high-quality YBCO films have been developed on single crystal substrates with the transport $J_{\mathrm{c}} \mathrm{S}$ up to $10^{6} \mathrm{~A} \mathrm{~cm}^{-2}$. In this study, the precursor solution stoichiometry was altered and its effects on superconducting properties were studied. The fluorine-free sol-gel-derived films on the $\mathrm{LaAlO}_{3}$ (LAO) substrate exhibited epitaxial growth with excellent in- and out-of-plane texture. Experimental details are reported on the sol-gel synthesis chemistry and XRD and TEM characterization of the YBCO thin films. Also discussed is the underlying formation mechanism of the YBCO phase during the synthesis.
\end{abstract}

(Some figures in this article are in colour only in the electronic version)

\section{Introduction}

In the development of superconducting coated conductors, the major approaches include vapour deposition (in situ) and solution synthesis (ex situ). While vapour deposition has resulted in high-quality thin films on various substrates, the solution methods offer a convenient and economical way of industrial scaling-up processing. Although the ex situ approaches have been traditionally viewed as thick film processes with less control in the film qualities, the breakthroughs in $\mathrm{BaF}_{2}$ processes, MOD-TFA, and MOCVD methods set outstanding examples for synthesizing superior films that are capable of carrying high transport currents [1-5] The solution approach has been shown to be most promising for high-rate processing of ReBCO in practical applications.

Usually ex situ routes involve two processing steps, whereby a precursor layer is first deposited either by ultrasonic spray pyrolysis, sol-gel spin, dip coating, or an ex situ $\mathrm{BaF}_{2}$ process. The precursor layer is subsequently heat treated to convert to a crystallized ReBCO layer in order to obtain the desired biaxial textures. In the ex situ $\mathrm{BaF}_{2}$ process, the precursor film is co-evaporated by e-beam from $\mathrm{Y}, \mathrm{Cu}$, and $\mathrm{BaF}_{2}$ sources, followed by an ex situ heat treatment process under a controlled humidified atmosphere. The 
exact mechanism of the heat treatment process is still under investigation. Solovyov et al [6] proposed that the metaloxifluoride precursor decomposes as the temperature increases in the presence of $\mathrm{H}_{2} \mathrm{O}$ vapour while releasing $\mathrm{HF}$. The decomposed precursor product is converted into the Y123 phase. Hence, it is important for the conversion process to go to a completion, which is generally a straightforward process for short samples. However, problems arise for longer samples where non-uniform YBCO conversion is reported [7]. This is thought to be due to the build-up of HF to a saturation level, leaving part of the precursor film unreacted. Recently, Lee et al [7] reported $90 \mathrm{~A} / \mathrm{cm}-\mathrm{w}, 1 \mathrm{~m}$ long with $0.82 \mu \mathrm{m}$ YBCO film on RABiTS and Feenstra [8] reported 270 A/cm-w for $3 \mathrm{~m}$ long and $3 \mu \mathrm{m}$ YBCO film on RABiTS.

In the early research of high temperature superconductivity, there were three commonly used solutions applied for the ReBCO deposition [9-12]:

(1) sol-gel synthesis that used 2-methoxyethanol as a reactant and solvent;

(2) hybrid processes in which acetylacetonates or diethanolamine were used to reduce alkoxide reactivity, and

(3) metal organic decomposition (MOD) techniques that employed high molecular weight precursors such as waterinsensitive carboxylates and 2-ethyl-hexanoates.

However, by using these early approaches, the transport $J_{\mathrm{c}} \mathrm{S}$ were found to be limited in the ReBCO films. It was believed that the carbon-containing precursors might result in the formation of stable $\mathrm{BaCO}_{3}$ at the grain boundaries [13]. In 1988, Gupta [4] reported a method using metal trifluoroacetate precursors, called the TFA method, to generate textured YBCO film on the crystal substrate. Mclntyre and Cima [5] further developed this method and high current densities were achieved in thin YBCO films.

The use of TFA salts appears to avoid the formation of $\mathrm{BaCO}_{3}$ because the stability of barium fluoride is believed to be greater than that of barium carbonate. Also, fluorine can be removed during the high-temperature anneal $\left(>650^{\circ} \mathrm{C}\right)$ in a humid, low oxygen partial pressure environment [14]. Currently, metal organic deposition using a trifluoroacetate salt (TFA-MOD) is a better known and well established solgel route attempted by several groups for coated conductor fabrication $[1,2]$. Spin or dip coating is usually used to deposit the precursors that are then calcined under various $\mathrm{O}_{2}$ partial pressures. High $J_{\mathrm{c}}$ values ranging from 6.7 to $7.5 \mathrm{MA} \mathrm{cm}^{-2}$ on single crystalline $\mathrm{LaAlO}_{3}$ substrates and 1.7-2.5 $\mathrm{MA} \mathrm{cm}^{-2}$ on IBAD-YSZ and on Hastelloy [15] have been reported.

Despite the great success in the TFA methods, synthesis issues are not entirely settled, especially for the problems of removing $\mathrm{BaCO}_{3}$ and related mechanisms. For instance, the TFA approach is a by-pass to avoid the formation of $\mathrm{BaCO}_{3}$ by using fluorine to substitute the carbon-containing precursors, whilst a problem is introduced with the use of fluorine as $\mathrm{BaF}_{2}$, which is difficult to decompose. Accordingly, the idea of reacting the $\mathrm{BaF}_{2}$ with water used in the TFA and e-beam $\mathrm{BaF}_{2}$ approaches suggests that carbon might be removed by a similar reaction as in the TFA route. In our recent studies, however, using a fluorine-free sol-gel approach involving trimethylacetate salts and proponic acid (TMAP) precursor solution, well textured, epitaxial YBCO thin films were synthesized [16-19]. The transport critical current density was found to steadily increase as the microstructure was improved in the YBCO thin film prepared by the fluorinefree sol-gel TMAP method. Hence, a high transport $J_{\mathrm{c}}$ was recently obtained of the order of $1 \mathrm{MA} \mathrm{cm}^{-2}$ at $77 \mathrm{~K}[18,19]$.

For the fundamental understanding of the synthesis chemistry, it is of great interest to comparatively study the processing routes of both TFA and TMAP. In the past, the critical point in solution synthesis of YBCO film was focused on the removal of carbon. It was believed that carbon could be removed from the material at a low temperature $\left(<400^{\circ} \mathrm{C}\right)$ in the burn-out stage in wet oxygen, and fluorine could then be removed at a higher temperature $\left(>700{ }^{\circ} \mathrm{C}\right)$ in a humid and low oxygen partial pressure environment [9-12]. However, the results from the TMAP approach have indicated that the technique allows the use of a carbon-containing precursor film to be reacted at $700-800{ }^{\circ} \mathrm{C}$ to obtain high- $J_{\mathrm{c}}$ films. This is achieved by specific processing conditions that allow for the complete removal of carbon. Therefore, in this study, we investigated the possibilities of decomposing $\mathrm{BaCO}_{3}$ by reacting with water at high temperatures in low oxygen partial pressure. In this way, the YBCO phase could be formed simultaneously. This process can be viewed as a direct solution to the problem existing universally in the fluorine-free methods.

In this study, experiments on the precursor stoichiometry and optimization of processing parameters were carried out. We present the experimental results on the effects of precursor stoichiometry and heat treatment on texturing and the superconducting properties of YBCO thin films.

\section{Experimental details}

The non-fluorine-based sol-gel YBCO solutions were developed in-house. The procedure is shown schematically in figure 1. For the precursor solution, stoichiometric yttrium trimethylacetate, barium hydroxide, and copper trimethylacetate powders were dissolved in a mixed propionic acid/amine solvent with an oxide concentration between 0.1 and $0.5 \mathrm{~mol}^{-1}$. The addition of amine was important because it greatly improved the solubility of the precursor powders in propionic acid. The stock solution was stable in air with a shelf life longer than two years. Xylenes of alcohols were used for dilution and controlling solution viscosity at 10-100 cP. The films on $\mathrm{LaAlO}_{3}$ (LAO) were deposited on (001) LAO single crystal substrates with dimensions $10 \times 10 \times 1 \mathrm{~mm}^{3}$ by spin coating at 3000-3500 rpm and were baked on a hot plate at 200-250 ${ }^{\circ} \mathrm{C}$ for several minutes.

Sample burn-out was performed in a quartz tube furnace. Humid furnace gas was generated and introduced by flowing the entrance gas though a large flask heated or cooled by a water bath. A programmed heating profile was used to burn out the gel film formed in the prior procedure. In this programme a slow ramp start at $190^{\circ} \mathrm{C}$ was employed to avoid explosive reaction and rough surface. With a low ramp speed $\left(<20^{\circ} \mathrm{C} \mathrm{min}^{-1}\right)$ the precursor was found to oxidize too rapidly in oxygen. The use of a slow ramp suppresses the vigorous oxidation of copper organic compounds and forms a smooth 


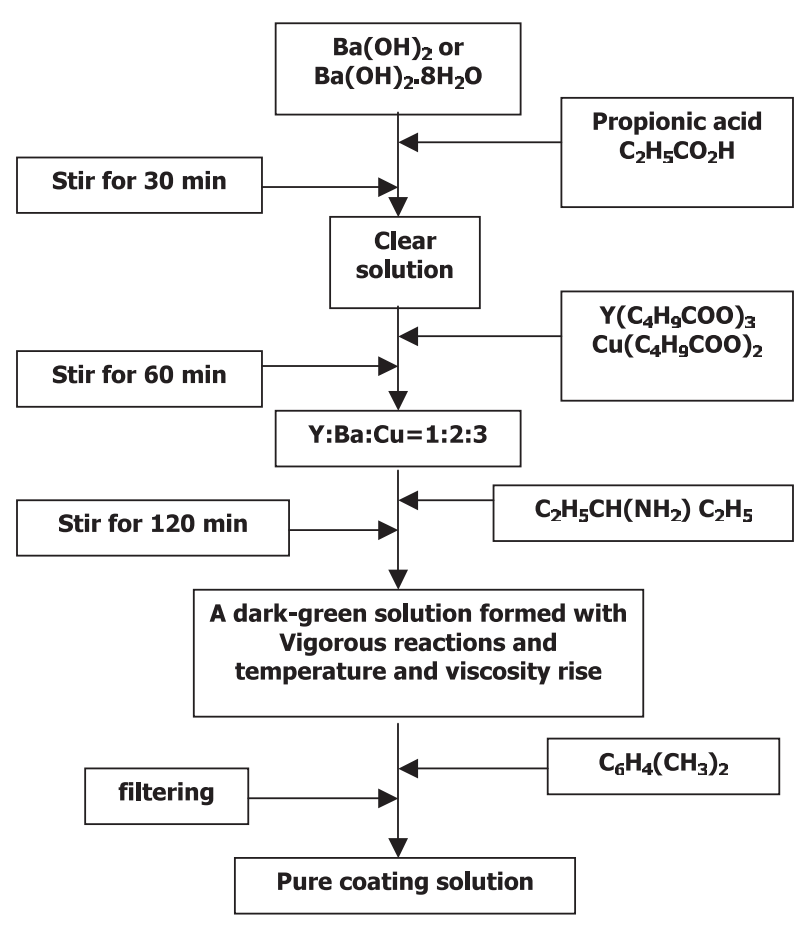

Figure 1. A diagram showing the solution precursor synthesis.

surface of burn-out films. Most of the carbon hydrides were removed in this stage.

After spin coating, the films were first calcined at $400{ }^{\circ} \mathrm{C}$ in wet nitrogen with $2 \%$ oxygen for $3 \mathrm{~h}$, then heat treated in a quartz furnace under humid nitrogen mixed with $200 \mathrm{ppm}$ oxygen. The temperature was increased from room temperature to $780{ }^{\circ} \mathrm{C}$ at the rate of $20^{\circ} \mathrm{C} \mathrm{min}{ }^{-1}$, then to $800{ }^{\circ} \mathrm{C}$ at the rate of $3{ }^{\circ} \mathrm{C} \mathrm{min}^{-1}$, dwelling at $800^{\circ} \mathrm{C}$ for $70 \mathrm{~min}$. Ten minutes before the dwelling process, a dry atmosphere was used. Then the temperature was decreased to $450{ }^{\circ} \mathrm{C}$ at the rate of $2.5^{\circ} \mathrm{C} \mathrm{min}^{-1}$. As the temperature was lowered to $525^{\circ} \mathrm{C}$, the atmosphere of $200 \mathrm{ppm}$ oxygen was switched to pure oxygen, dwelling at $450{ }^{\circ} \mathrm{C}$ for $60 \mathrm{~min}$. The samples were furnace-cooled to room temperature.

A Philip x-ray diffractometer with $\mathrm{Cu} \mathrm{K} \alpha$ radiation was used to carry out the texture investigations. The x-ray wavelength was $1.54 \AA$ with a beam size of $3 \mathrm{~mm}$. Scanning electron microscopy (SEM) experiments were performed on a Hitachi 2000. Some specimens were also examined by scanning electron microscopy in a JEOL JSM 5400 microscope that was operated at $10 \mathrm{kV}$. No conductive coating was applied. The high-resolution TEM (HRTEM) experiments were performed on a JEOL 2010F TEM. Resistivity measurements were carried out down to liquid helium temperature using a standard four-probe method. The transport $J_{\mathrm{c}}$ was determined with a voltage criterion of $10 \mu \mathrm{V} \mathrm{cm}^{-1}$.

\section{Results and discussion}

YBCO sol-gel solutions with different stoichiometry (Y:Ba:Cu) were applied to $\mathrm{LAO}$ substrates via spin coating. Using wet chemistry we have measured the compositions of the solutions that are listed in table 1 . As can be seen in this
Table 1. Compositions of three solutions.

\begin{tabular}{llllll}
\hline & \multicolumn{5}{c}{ Solution } \\
\cline { 2 - 6 } & $\mathrm{A}$ & $\mathrm{B}$ & $\mathrm{C}$ & $\mathrm{D}$ & $\mathrm{E}$ \\
\hline $\mathrm{Y}^{\mathrm{a}}$ & 1.00 & 1.00 & 1.0 & 1.00 & 1.00 \\
$\mathrm{Ba}$ & 2.00 & 2.00 & 2.08 & 2.02 & 4.17 \\
$\mathrm{Cu}$ & 3.02 & 3.19 & 3.25 & 4.51 & 7.02 \\
\hline
\end{tabular}

${ }^{\mathrm{a}}$ Using element $\mathrm{Y}$ as reference.

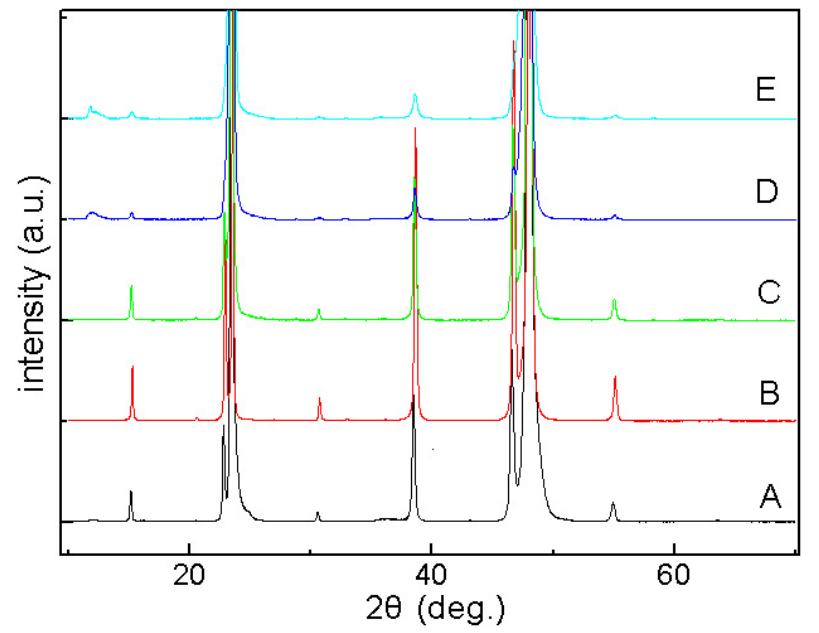

Figure 2. XRD spectra of YBCO films derived from solutions with different stoichiometry on LAO substrate.

table, the solutions are altered from near-stoichiometry 1:2:3 (solution A, B, C) to off-stoichiometry 1.00:2.02:4.51 (solution D), and 1.00:4.17:7.02 (solution E). The Cu-rich compositions were investigated as the $\mathrm{Cu}$ organic salts were volatile during the baking and calcining processes. The high volatility of the copper organic could lead to $\mathrm{Cu}$ loss in the films [5, 6], which was confirmed by DTA-TGA measurements and EDX analysis in our experiments.

Using the film syntheses and heat-treatment procedures described in the experimental details, we obtained x-ray diffraction (XRD) patters of these thin films on LAO substrate as shown in figure 2. As can be seen in figure 2, all of the (001) peaks of the YBCO films exhibit strong intensities, indicating a well-textured, $c$-axis oriented grain structure, especially for the films from solution B with a stoichiometry of 1.00:2.00:3.19.

The values of FWHM (full width at half maximum) of the (005) rocking curves are smaller than $1.5^{\circ}$, demonstrating a high degree of $c$-axis orientation. The films from solution B have smaller FWHM values of about $0.5^{\circ}$, as shown in figure 3 . The (103) phi scan of the films shows four-fold symmetry with FWHM of $0.6^{\circ}$, indicating a good in-plane texture. In the (103) pole figures of the films (figure 4), only four small poles are located on the correct positions, confirming that the YBCO phase grows epitaxially on the LAO substrate.

The superconducting properties of the thin films resulting from above solutions were characterized by using resistivity measurements. The effect of precursor stoichiometry on the superconducting transitions and normal state resistivity can be seen from figure 5(a). For the well-off-stoichiometry film (solution E), the normal state exhibits a semiconducting behaviour that is improved by tuning the $\mathrm{Ba}$ and $\mathrm{Cu}$ content 
The development of YBCO thin films using a fluorine-free sol-gel approach for coated conductors

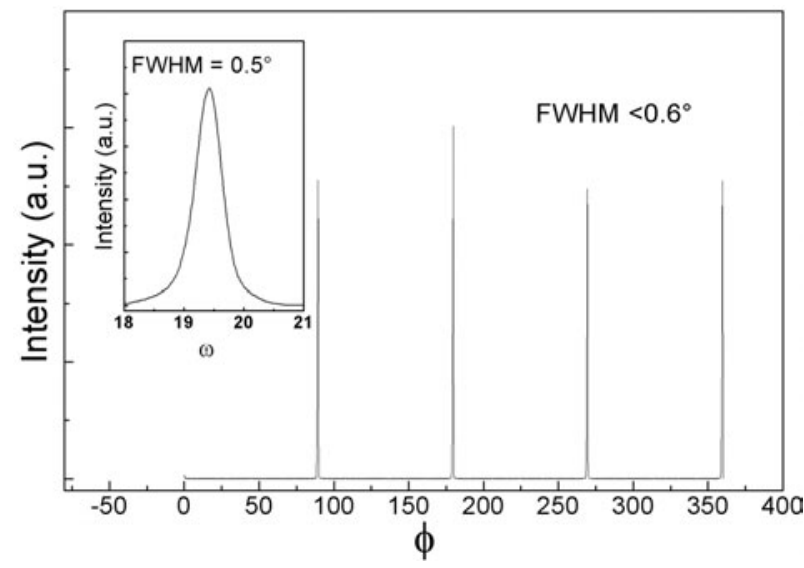

Figure 3. (103) phi scan and (005) omega scan of the YBCO film from solution B with stoichiometry Y:Ba:Cu of 1.00:2.00:3.19.

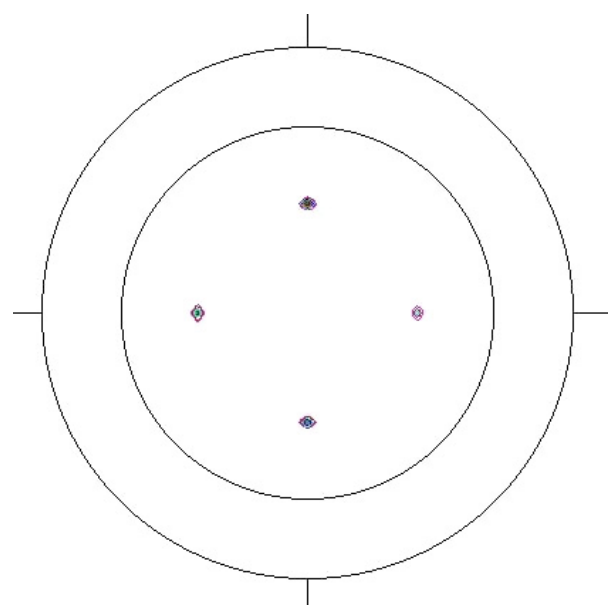

Figure 4. (103) pole figure of the YBCO film from solution B.

in solution D. However, further tuning the stoichiometry in solutions $\mathrm{A}, \mathrm{B}$, and $\mathrm{C}$ has resulted in a sharp superconducting transition near $90 \mathrm{~K}$. The resistivity measurement performed on another sample with solution B again shows a sharp transition at $90 \mathrm{~K}$ (see figure 5(b)). As expected, the optimum stoichiometry lies within an exact precursor composition. In this study the films with a stoichiometry 1.00:2.00:3.19 (Y:Ba: $\mathrm{Cu}$ ) may be optimal for a high degree of biaxial texture, microstructure, and superconducting properties. We chose this solution for the experiments in the processing parameter optimization.

Figure 6 shows the SEM micrograph of the YBCO thin film (processed with solution B) surface morphology. This figure shows smooth $c$-axis oriented film $\left(780^{\circ} \mathrm{C}, 200 \mathrm{ppm}\right)$. As can be seen in figure 6, the surface of the film is quite dense, with a few particles that have been identified as copper rich by energy dispersive spectroscopy. Careful SEM examination showed no noticeable microcracks in the film, except a few voids that are common characteristics of sol-gel films.

Epitaxial growth of YBCO thin films on LAO was expected due to the single crystal substrate. The transmission electron microscopy (TEM) study showed well-established epitaxial growth in fluorine-free sol-gel YBCO thin films on the LAO substrate. Figure 7(a) shows the TEM image of the cross-sectional area of the thin film from solution B,
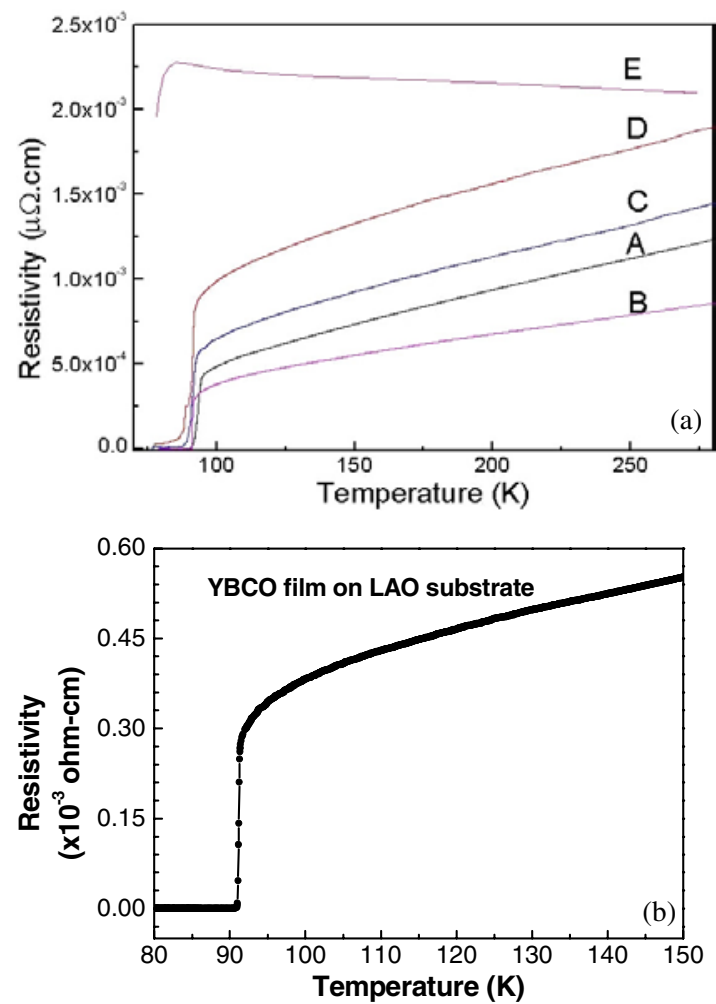

Figure 5. (a) Resistivity versus temperature for the YBCO films on LAO made from solutions A, B, C, D, and E, and (b) resistivity versus temperature for another thin film sample made from solution B.

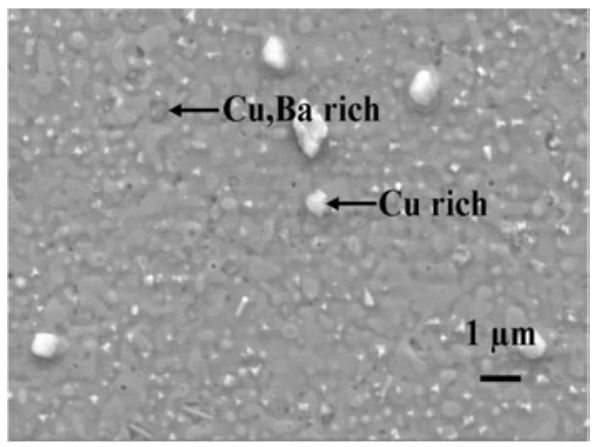

Figure 6. SEM micrograph showing the top surface of YBCO films on LAO.

indicating a smooth film surface and interface. The highresolution TEM image reveals a coherent interface structure, as shown in figure 7(b). Based on the TEM data, the thickness of the epitaxial film was estimated to be $0.5 \mu \mathrm{m}$. In figure 8 the selected area electron diffraction (SAED) pattern shows a clear lattice-matching interface between the LAO substrate and the YBCO phase with $\mathrm{LAO}_{001} \| \mathrm{YBCO}_{001}$. However, in the $a$-axis oriented film, the interface structure exhibits an entirely different feature, as can be seen in figure 9. Figure 9 shows the initial epitaxial growth of both $a$ - and $c$-axis oriented grains at the interface. This interface structure suggests that both orientations ( $a$ - and $c$-axis) could take place simultaneously directly from the LAO substrate.

The transport critical current densities of these films have reached values of the order of $10^{5} \mathrm{~A} \mathrm{~cm}^{-2}$ at $77 \mathrm{~K} \mathrm{[17].} \mathrm{The}$ 

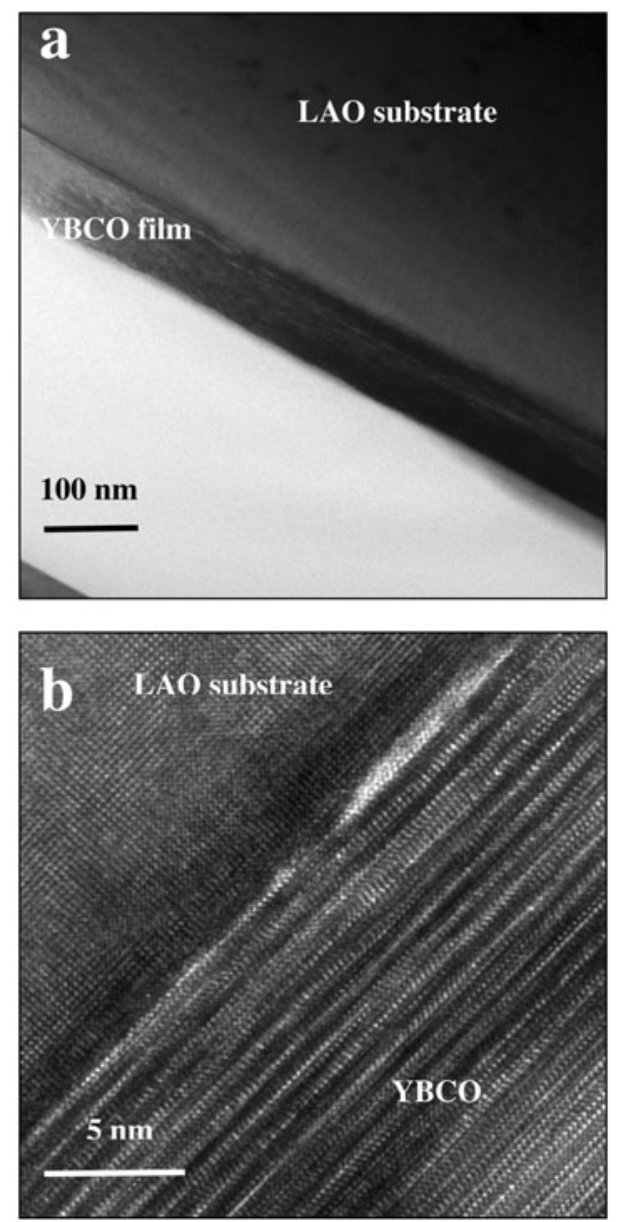

Figure 7. (a) TEM image showing the interface of the YBCO thin film, and (b) high resolution image of the same interface.

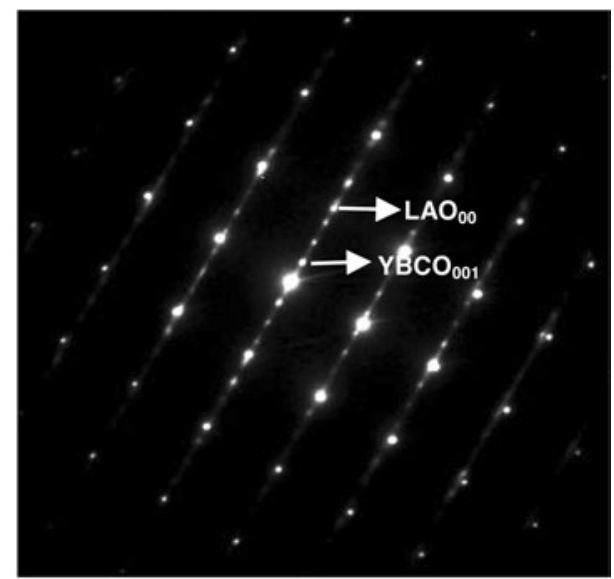

Figure 8. SAED pattern showing well-established epitaxial growth of YBCO film on LAO substrate with a coherent interface lattice structure: $\mathrm{LAO}_{001} \| \mathrm{YBCO}_{001}$.

most recent studies by $\mathrm{Xu}$ et al have shown much higher $J_{\mathrm{c}} \mathrm{s}$ over $10^{6} \mathrm{~A} \mathrm{~cm}^{-2}$ at $77 \mathrm{~K}$ by using a similar fluorinefree method $[18,19]$. These results show that the fluorinefree method can serve as an effective alternative to the TFA approach. In the TFA approach, the issue of removing $\mathrm{BaCO}_{3}$ is dealt with by introducing fluorine. However, $\mathrm{BaF}_{2}$ is difficult to decompose during the synthesis. Furthermore, the fluorine-

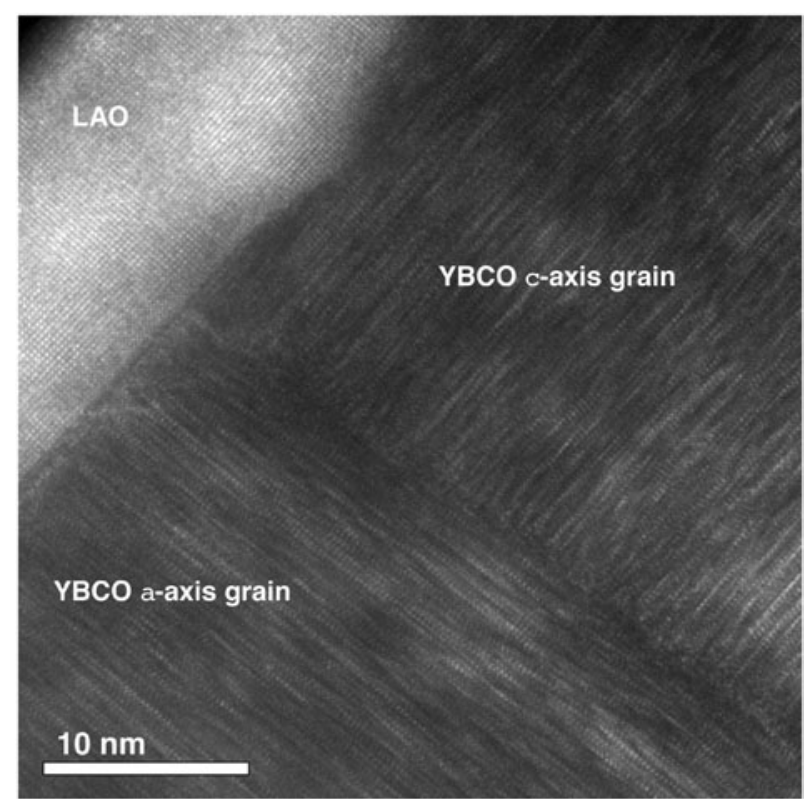

Figure 9. TEM image showing the initial growth of both $a$-axis and $c$-axis oriented YBCO grains from the LAO substrate.

containing precursor is sensitive to water vapour, and the films tend to roughen when exposed to a humid environment at room temperature even for tens of seconds. This precursor instability introduces great variations in solution delivering, storing and handling.

According to the results shown in this study, there are possibilities of decomposing $\mathrm{BaCO}_{3}$ by reacting with water at high temperatures in low oxygen partial pressure. One of the possibilities is the reaction during slow heating in a humid furnace:

$$
\mathrm{BaCO}_{3}+\mathrm{H}_{2} \mathrm{O} \rightarrow \mathrm{Ba}(\mathrm{OH})_{2}+\mathrm{CO}_{2} \uparrow
$$

This reaction has been confirmed in a recent study by Xu [19]. The results of this study suggest that it is possible that the $\mathrm{BaCO}_{3}$ phase is transferred to $\mathrm{Ba}(\mathrm{OH})_{2}$ phase above $420^{\circ} \mathrm{C}$, and remains up to $640^{\circ} \mathrm{C}$, at which point it begins to react with other oxides to form the Y123 phase. In a low humidity environment, the barium-containing phase usually experiences the formation of $\mathrm{Ba}(\mathrm{OH})_{2} \cdot x \mathrm{H}_{2} \mathrm{O}$ at a temperature below $400{ }^{\circ} \mathrm{C} . \mathrm{BaCO}_{3}$ phase forms at an intermediate temperature. The YBCO phase appears and becomes stable at a temperature above $\sim 700^{\circ} \mathrm{C}$. But in a high humidity situation, $\mathrm{BaCO}_{3}$ phase forms at a temperature near $400^{\circ} \mathrm{C}$. It then reacts with water to form $\mathrm{Ba}(\mathrm{OH})_{2}$, a melting phase, at an intermediate temperature. At high temperatures above $700^{\circ} \mathrm{C}$, this liquid phase reacts with other oxides to form YBCO. The key reactions are summarized below [19].

$$
\mathrm{Cu}(\text { TMAP }) \rightarrow \mathrm{Cu}+\mathrm{O}_{2} \rightarrow \mathrm{Cu}_{2} \mathrm{O}+\mathrm{O}_{2} \rightarrow \mathrm{CuO} .
$$

For low humidity:

$$
\begin{aligned}
& \mathrm{Ba}(\mathrm{TMAP}) \rightarrow \mathrm{Ba}(\mathrm{OH})_{2} \cdot x \mathrm{H}_{2} \mathrm{O}+\mathrm{CO}_{2} \rightarrow \\
& \quad \mathrm{BaCO}_{3}+\mathrm{CuO}+\mathrm{Y}_{2} \mathrm{O}_{3} \rightarrow \mathrm{YBa}_{2} \mathrm{Cu}_{3} \mathrm{O}_{7-\delta}+\mathrm{O}_{2} .
\end{aligned}
$$

For high humidity:

$$
\begin{aligned}
& \mathrm{Ba}(\mathrm{TMAP}) \rightarrow \mathrm{BaCO}_{3}+\mathrm{H}_{2} \mathrm{O} \rightarrow \\
& \quad \mathrm{Ba}(\mathrm{OH})_{2}+\mathrm{CuO}+\mathrm{Y}_{2} \mathrm{O}_{3} \rightarrow \mathrm{YBa}_{2} \mathrm{Cu}_{3} \mathrm{O}_{7-\delta}+\mathrm{O}_{2} .
\end{aligned}
$$


The development of YBCO thin films using a fluorine-free sol-gel approach for coated conductors

With regard to the orientation of the YBCO grains, the only possibility for the growth of $c$-axis oriented grains is to suppress $a$-axis oriented grains. In the TFA method, the $\mathrm{BaF}_{2}$ phase could be stable up to $\sim 700^{\circ} \mathrm{C}$, below which the formation of $\mathrm{YBCO}$ phase is difficult. This means that the formation of $a$-axis oriented YBCO grains (usually below $700^{\circ} \mathrm{C}$ ) is circumvented due to limited barium source. In a non-fluorine route, we expect the formation of $\mathrm{BaCO}_{3}$, though it may not be as stable as that of $\mathrm{BaF}_{2}$. However, we believe that there is a substantial amount of liquid phase, $\mathrm{Ba}(\mathrm{OH})_{2}$, that exists up to $700^{\circ} \mathrm{C}$ near which the formation of YBCO is possible. Under a low water partial pressure, YBCO phase forms in a relatively lower temperature range from $\mathrm{BaCO}_{3}$ with $a$-axis orientation.

Another factor that affects the orientation of the grains is the heating rate. It has been found that slow heating during the heating up between $450-700{ }^{\circ} \mathrm{C}$ could induce the crystallization of second phases such as $\mathrm{BaCO}_{3}, \mathrm{BaCuO}_{2}$, $\mathrm{Y}-\mathrm{Cu}-\mathrm{O}$ which will segregate the precursor film and reduce the driving force for $\mathrm{YBCO}$ formation. Therefore a relatively high heating rate up to $40^{\circ} \mathrm{C} \mathrm{min}{ }^{-1}$ is preferred to avoid the formation of $a$-axis grains.

\section{Conclusion}

In summary, we have deposited YBCO thin films on LAO substrate using a new, fluorine-free sol-gel approach. It has been found that the precise stoichiometry of the precursor solution is critical in achieving high-quality YBCO thin films. Both XRD and SEM results have shown that these sol-gel YBCO films on LAO exhibit biaxial texture. Our previous studies have shown a $J_{\mathrm{c}}$ of the order of $10^{6} \mathrm{~A} \mathrm{~cm}^{-2}$ at $77 \mathrm{~K}$ from these fluorine-free sol-gel YBCO films. It is found that the $\mathrm{BaCO}_{3}$ phase can be converted to $\mathrm{Ba}(\mathrm{OH})_{2}$ phase above $420^{\circ} \mathrm{C}$. Near $640^{\circ} \mathrm{C}$, this barium-containing phase reacts with other oxides to form the Y123 phase. The $a$-axis oriented YBCO grains can be suppressed by a high heating rate to avoid the crystallization of second phases.

\section{Acknowledgments}

This work is partially supported by the 'Chun Hui Plan' of the Chinese Education Ministry, China Postdoctoral Science Foundation, and Australian Research Council.

\section{References}

[1] McIntyre P C, Cima M J and Roshko A 1995 Epitaxial nucleation and growth of chemically derived $\mathrm{Ba}_{2} \mathrm{YCu}_{3} \mathrm{O}_{7-Y}$ thin-films on (001) $\mathrm{SrTiO}_{3}$ J. Appl. Phys. 77 5263-72

[2] Smith J A, Cima M J and Sonnenberg N 1999 High critical current density thick MOD-derived YBCO films IEEE Trans. Appl. Supercond. 9 1531-4
[3] Araki T, Yamagiwa K and Hirabayashi I 2001 Fabrication of $\mathrm{YBa}(2) \mathrm{Cu}(3) \mathrm{O}(7-x)$ film by metalorganic deposition method using trifluoroacetates and its process conditions Cryogenics $\mathbf{4 1}$ 675-81

[4] Gupta A, Jagannathan R, Cooper E I, Giess E A Landman J I and Hussey B W 1988 Superconducting oxide-films with high transition-temperature prepared from metal trifluoroacetate precursors Appl. Phys. Lett. 52 2077-9

[5] McIntyre P C, Cima M J, Ng M F, Chiu R C and Rhine W E 1990 Texture development in $\mathrm{Ba}_{2} \mathrm{YCu}_{3} \mathrm{O}_{7-X}$ films from trifluoroacetate precursors J. Mater. Res. 5 2771-9

[6] Solovyov V F, Wiesmann H J, Wu L J, Zhu Y M and Suenaga M 2000 Kinetics of $\mathrm{YBa}_{2} \mathrm{Cu}_{3} \mathrm{O}_{7-x}$ film growth by postdeposition processing Appl. Phys. Lett. 76 1911-3

[7] Lee D F et al 2002 Continuous reel-to-reel ex situ processing of YBCO on textured substrates Int. Workshop on Processing and Application of Superconductors (Gatlinburg, TN, USA)

[8] Feenstra R 2002 YBCO by ex situ BaF2 process Int. Workshop on Processing and Application of Superconductors (Gatlinburg, TN, USA)

[9] Schwartz R W 1997 Chemical solution deposition of perovskite thin films Chem. Mater. $92325-40$

[10] Kumagai T et al 1993 Japan. J. Appl. Phys. 32 L1602-5

[11] Lange F F 1996 Chemical solution routes to single-crystal thin films Science 273 903-9

[12] Goyal A 2002 Next generation HTS conductors Non-Fluorine Based Solution Techniques to Grow Superconducting $\mathrm{YBa}_{2} \mathrm{Cu}_{3} \mathrm{O}_{7-x}$ Films - a Review ed M Paranthaman (New York: Plenum)

[13] Parmigiani F, Chiarello G, Ripamonti N, Goretzki H and Roll U 1987 Observation of carboxylic groups in the lattice of sintered $\mathrm{Ba}_{2} \mathrm{YCu}_{3} \mathrm{O}_{7-Y}$ high- $T_{\mathrm{c}}$ superconductors Phys. Rev. B 36 7148-50

[14] McIntyre P C, Cima M J, Smith J A, Hallock R B, Siegal M P and Phillips J M 1992 Effect of growth-conditions on the properties and morphology of chemically derived epitaxial thin-films of $\mathrm{Ba}_{2} \mathrm{YCu}_{3} \mathrm{O}_{7-Y}$ on (001) $\mathrm{LaAlO}_{3}$ J. Appl. Phys. 71 1868-77

[15] Araki T, Yuasa T, Kurosaki H, Yamada Y, Hirabayashi I, Kato T, Hirayama T, Iijima Y and Saito T 2002 High- $J$ (c) $\mathrm{YBa}_{2} \mathrm{Cu}_{3} \mathrm{O}_{7-x}$ films on metal tapes by the metalorganic deposition method using trifluoroacetates Supercond. Sci. Technol. 15 L1-3

[16] Xu Y L, Shi D L, McClellen S, Buchanan R, Wang S X and Wang L M 2001 Deposition of epitaxial YBCO thin film on single domain YBCO substrate for the development of RF components IEEE Trans. Appl. Supercond. 11 2865-8

[17] Shi D L, Xu Y L, Wang S X, Lian J, Wang L M, McClellan S M, Buchanan R and Goretta K C 2002 Deposition and interface structures of YBCO thin films via a non-fluorine sol-gel route Physica C 371 97-103

[18] Xu Y, Goyal A, Rutter N A, Shi D, Paranthaman M, Sathyamurthy S, Martin P M and Kroeger1 D M 2003 Fabrication of high $J \mathrm{c} \mathrm{YBa}_{2} \mathrm{Cu}_{3} \mathrm{O}_{7-d}$ films using a fluorine-free sol gel approach J. Mater. Res. 18 (3)

[19] Xu Y 2003 High Jc epitaxial YBCO films though a non-fluorine approach for coated conductor applications PhD Dissertation University of Cincinnati 